\title{
Defining Equity Criteria for Determining Fare Zones in Integrated Passenger Transport
}

\author{
Denis Šipuš $\left(\mathbb{D},{ }^{1}\right.$ Borna Abramović $\mathbb{D}^{1},{ }^{1}$ and Martina Jakovčić $\mathbb{D}^{2}$ \\ ${ }^{1}$ University of Zagreb, Faculty of Transport and Traffic Sciences, Zagreb, Croatia \\ ${ }^{2}$ University of Zagreb, Faculty of Science, Department of Geography, Zagreb, Croatia \\ Correspondence should be addressed to Denis Šipuš; denis.sipus@fpz.unizg.hr
}

Received 7 June 2021; Revised 27 January 2022; Accepted 17 February 2022; Published 4 March 2022

Academic Editor: Shamsunnahar Yasmin

Copyright (c) 2022 Denis Šipuš et al. This is an open access article distributed under the Creative Commons Attribution License, which permits unrestricted use, distribution, and reproduction in any medium, provided the original work is properly cited.

Fare system models in public transport are researched based on the fact that they represent a direct and flexible instrument of influencing passenger behavior and covering public transport costs, which contributes to the sustainability of public passenger transport. Integrated passenger transport, as a concept of public transport management that uses a zonal fare system, defines transport service prices within a fare zone. An analysis of existing fare systems reveals that current systems do not offer equitable access for passengers and that the transport service is not available to everyone. To resolve the issue of the transport disadvantage of potential passengers, society and space, fare system models must be changed to provide equity for disadvantaged participants of the system. This would do away with transport and social disadvantage in the analyzed region. The aim of this research is to define equity criteria in determining fare zones in integrated passenger transport. This is a precondition for an equitable fare model which would ensure an impartial and fair charge of transport services within zones.

\section{Introduction}

Devising fare systems in integrated passenger transport is essential for understanding and motivating service users. It also helps us to understand transport operators and transport authorities engaged in the system. In public transport, as well as in its integrated transport concept, there are several ways to define fares [1], the most popular of which are (1) distance fare system, (2) uniform fare system, and (3) zone fare system. In case of the latter, an area is divided into subregions based on concentric circles, hexagons, and other irregular shapes that are determined by various parameters. Fares are determined based on the number of zones crossed in a single journey and on the cost of each zone $[2,3]$. These systems must be as precise as possible in representing the fares of a distance fare system, which is generally considered the most equitable compared to the rest [4]. This is particularly important when switching from a zone to a distance fare model. In the transition from a distance-based to a zone fare model, profit generated by passenger transport must not decrease. At the same time, fares cannot rise as they would reduce passenger demand [5]. Determining a fare within a zone fare system based on equity ensures equal access to all public transport users, as well as a balanced development of a region in which the public transport service is provided. Devising an equitable fare model in integrated passenger transport requires us to identify the equity criteria of defining fare zones. They can be identified using three groups of development criteria: (1) demographic, (2) economic, and (3) transport criteria. Particular attention should be paid to transport development criteria which greatly affect transport equity and disadvantage of certain areas and groups of people [6]. Identifying equity criteria of defining fare zones in integrated passenger transport is a prerequisite for establishing the relevant criteria for devising equitable fare zones.

Public passenger transport in its essence needs to ensure equal access to all transport users in the market and ensure that no user is left without the possibility of using the system [7]. Equal availability in current fare systems was presented as an equal fare per kilometer for a transport service user. However, equal availability was not observed from the standpoint of equal transport, economic, and demographic development in areas where public transport service is 
provided. This new way of thinking leads to changes within fare system models, with an aim to improve the position of disadvantaged participants, thus removing transport disadvantage of space and society that commutes in these areas. Equitable fare models aim to prevent transport disadvantage by appealing to disadvantaged users [8].

\section{Literature Review}

Fare planning in public passenger transport is a demanding optimization process. The various ways of approaching fare planning models are reflected in the desires of transport service users as well as operational costs of transport service providers [9]. Defining fares can have a significant impact on user behavior and how they commute, which is why fare systems must be objectively devised so that they have a positive impact on transport demand [10].

When designing such systems, Hamacher and Schöbel [1] emphasize the need to achieve transport-equitable zone fares. Chen et al. [11]; on the other hand, propose models for determining optimal conditions to ensure the maximization of societal benefit in transport. These measures would require substantial changes to the overall fare system and transport supply.

Most often, these include lower fares and more frequent departures. The measures generate an increased deficit for transport service providers and authorities due to a greater demand for subsidized public transport, as argued by Carny et al. [12], Guzman et al. [13] and Holmgren [14]. Issues arise at competent bodies with greater financial restraints. Houston and Tilley [15] emphasize the importance of optimizing fare systems for special groups of passengers such as the youth, persons with disabilities, women, and the elderly. Gašparović [16] hints at the issue of attributing an individual or a group with limited social importance as a result of restricted access to the transport system. Martens [17] advocates the importance and duty of transport authorities to ensure equitable planning and charging of public transport services from a social and spatial aspect. They argue for raising awareness about the need to achieve and enable sufficient mobility and access for every individual and social group.

An analysis of papers on designing zone fare systems in public transport [18-22] reveals a number of ways to determine a price in a fare zone, for which every transport authority determines requirements based on mathematical models. Models for planning fare systems in public transport purposefully maximize demand, revenue, profit, and social benefits. Four fare planning models are proposed, including different aspects whose adaptation depends on specific planning points of view. The simplest fare planning model is a revenue maximization model based on particular user interests or policy objectives. The second model is adjusted for profit maximization and includes operating costs on the lines. It can be concluded that such a model represents the difference between the model for maximizing revenue and operating costs caused by travel. The third model is to maximize the demand for transportation services. As a rule, in the literature, demand is viewed in passenger-kilometers.
In addition to the mentioned models, maximizing the functioning of social utility stands out. It represents the sum of the benefits of the transport service provider and the benefits of the transport user. The benefits of the transport service provider represent profit (revenue minus cost). In contrast, the benefits of the transport user are the difference between the generalized price that is acceptable to the user and the actual generalized price which the user pays for the received transport service. The influence of political, social, and external constraints in the choice of fare planning model is emphasized. The biggest disadvantage of all these models is that there is no equity in planning fare model.

One of the crucial advantages of creating and introducing an equity fare system should be seen in reducing evaders. In paper [23] give an exhaustive and excellent review of the literature about fare evasion in public transport systems. They said that fare evasion produces a relevant economic loss, social inequity, and increased levels of violence affecting individual security. The fare evaders could be classified into six categories: (1) people who have no choice; (2) gamblers who are not likely to meet inspectors; (3) ideological opponents who challenge the inspectors; (4) dissatisfied users about service quality; (5) cheaters pretending to pay the fine, but never pay; (6) people having difficulties in understanding the fare structure. Low-income people are often unable to pay for trips of daily necessity, and fare evasion could be perceived as their economic benefit. Malicious passengers can maximize their benefits without paying the fare. Let's consider that a new equity fare system considers the economic criteria of development. It can be concluded that it will reduce fare evasion because transportation will be more accessible to them.

An overview of literature and analysis of existing fare systems leads us to conclude that distance-based and zone fare systems do not provide equitable access to passengers and that the transport service is not available to everyone. Given that access refers to the state in which the financial cost of a journey does not represent a burden and lack of access for individuals and groups, it can be established that distance-based and zone fare systems are not completely available to all users. An individual or a group of people that reside in an area with exceptionally poor public transport service or people with low income cannot use the public transport service [24]. This, in turn, renders public transport inaccessible, and leaves people disadvantaged. Equally, public transport availability which mainly refers to departure frequency is unachieved if there is no user demand [25].

The works mentioned above on the design of zone fare systems do not consider the entire aspect of equity, so the current models do not even result in equity charging. Equity refers to the fairness which impacts (benefits and costs) are distributed. Transport planning decisions often have significant equity impacts that should be considered in planning phases. Evaluating these can be challenging because there are two types of equity and effects to consider and various ways to measure them. Horizontal equity assumes that people with similar needs and abilities should be treated equally and vertical equity assumes that disadvantaged groups receive a more significant share of resources. 
According to literature review the research gap can be found in the missing methodological approach for developing equity fare model. To achieve a new scientific contribution to the existing research is necessary to consider all the criteria that potentially affect equity and then define the essential criteria for developing an equity fare model. This paper will address the important first step of developing equity fare model and that is to define equity criteria.

To resolve the said issue of transport disadvantage, fare system models must be changed to ensure equity for the disadvantaged, and other participants. This would prevent transport disadvantage of regions and society that commutes in the region.

\section{Methodology}

Equity criteria of determining fare zones in integrated passenger transport comprise a system of interacting elements. They represent a set of organized elements whose common purpose is to ensure equitable charge. Due to the complexity of current systems, systemic analysis and modeling of dynamic systems are advised. System dynamics is an improved understanding of complex systems [26]. It is an interdisciplinary method because it encompasses the findings in other fields-from mathematics and IT to psychology and organization methods. This makes it crucial to analyze social systems and movements within.

System dynamics modeling [27] examines the features of complex dynamic systems with feedback. A feedback system is a closed loop of cause and effect, whereby the cause brings about consequences that affect the cause itself. The most important conceptual models in a discrete simulation are the activity cycle diagram and a Petri net, while flow diagrams and causal loop diagrams are considered conceptual illustrations of system dynamics models.

A causal loop diagram (CLD) is an important representation of a system dynamics model used to visualize the feedback of system variables. It ensures a visualization of cause-effect relationships between components of the system and is largely used in scientific and research work. Feedback is one of the most important terms in system dynamics as it determines the dynamics of the system. Devising a CLD requires caution because of the complexity of systems. The construction includes [27] variables connected by arrows that indicate the direction of the loop, that is, the causal effect between the variables. Each causal loop (Table 1) is marked by "+" or "-", which indicates the change in the dependent variable when the independent variable changes. A positive reinforcement loop is the one at which an increase in cause leads to an increase in effect (or the other way around), and the negative reinforcement loop means that an increase in cause will lead to a decrease in effect (or the other way around). Two or more chained cause-effect loops comprise an important loop which indicates that a feedback loop is positive (+) or $R$ loop. The second feedback loop can also be negative $(-)$ or balancing. An important loop is indicated using an identifier. A positive reinforcement loop $(R)$ is the one at which variables act reversibly on themselves in a single direction which results in a constant increase or decrease of the values of said variables. In a negative reinforcement loop $(B)$, loop elements cause a change in direction which results in the system striving for a balance. The positivity or negativity of a feedback loop depends upon the cause-effect loops within the loop.

The rule is that if all cause-effect relationships within the loop are positive, the feedback loop is positive. If within the loop there is a single or a few negative loops, the odd or even number of them decides whether the feedback look is positive (even) or negative, odd.

Causal loop diagram will be used to determine the equity criteria for determining fare zones in integrated passenger transport.

\section{Case Study}

Causal loop diagrams [28] are an excellent tool for outlining the central structure of a system and finding the underlying causal relationships in the system structure. It is proposed that the model be built in stages-several smaller causal loop diagrams whereby each corresponds to one part of the dynamic issue being outlined. It is desirable to devise a separate diagram for each important loop because only then can these diagrams be detailed enough the illustrate how variables relate to one another. The ultimate causal loop diagram is obtained by putting together the pieces of causal loop diagrams of some dynamic issues.

Equity fare criteria have been outlined in the paper [6], and they are a foundation for solving the issues that impact equity in integrated passenger transport. They put the demographic, economic, and transport criteria in correlation with a equity fare system and make it possible to determine a different zonal charging in various demographic, economic, and transport development regions. Equity zonal charging aims to ensure overall evenness by limiting transport disadvantage and giving more attention to the regions that are in less favorable position.

The structure of feedback loops in the system of demographic developmental criteria can be efficiently outlined by using systemic dynamics. The model of systemic dynamics of demographic developmental criteria needs to be devised by using three smaller causal loop diagrams which can be merged into a single ultimate model in the final stage. The first causal loop diagram is related to population dispersion (Figure 1.a). The Population Dispersion variable directly impacts the demographic development of a given area. The variable that can quantify population dispersion is Population Density which indicates the number of people per unit of area. In other words, Population Density communicates to Population and Surface Area variables, respectively. Surface Area and Population Density are negatively linked because the increase in one leads to a decrease in the other. Population is affected by Birth Rate, Death Rate, Immigration, and Emigration, among which there are also feedback loops. Birth Rate and Population, as well as Immigration and Population are linked by a positive loop $(R)$ because all causal-effect loops within the loop are positive. Death Rate and Population, as well as Emigration and Population, include a negative (balancing) loop because of the uneven number of negative causal-effect loops. 
TABLe 1: Symbols, meanings, examples, and charts in causal loop diagrams [27].

Increase in $X$ variable leads to increase in $Y$ variable

Loop identifier: positive loop $(R)$

Loop identifier: negative (balancing) loop

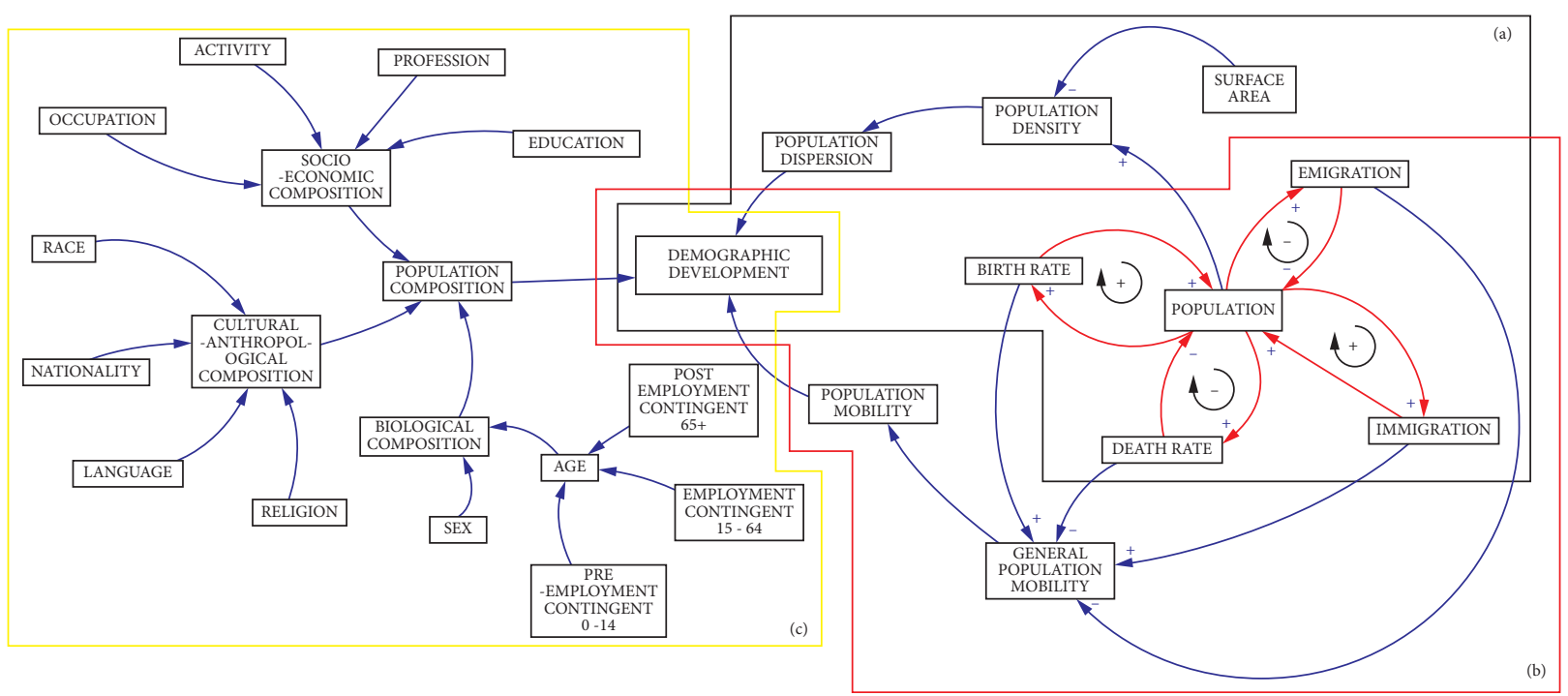

FIGURE 1: Structure of feedback loops (causal loop diagram) in the system of demographic developmental criteria.

Population Mobility includes a different causal loop diagram (Figure 1.b). The demographic development of an area is directly impacted by the Population Mobility variable which is a causal loop with General Population Mobility. The latter can be used to quantify population mobility and is used to outline population mobility at a period between two censuses. General Population Mobility communicates to Birth Rate and Death Rate, Immigration, and Emigration. Said variables are connected by causal loops with change direction towards General Population Mobility. The communication between General Population Mobility and Birth Rate, and General Population Mobility and Immigration sets up a positive loop because the increase in the first variable leads to an increase in the second. However, the communication between General Population Mobility and Death Rate, that is, General Population Mobility and Emigration shows a negative loop since an increase in the first variable leads to a decrease in the second. A partial occurrence of the same variables is noticed in the first and second causal loop diagrams, which will at the final stage (final model) contribute to the merge of two causal loop diagrams.

The third causal loop diagram is related to population composition (Figure 1.c). Population Composition directly affects an area's demographic development. It is comprised of the following variables: Socio-Economic Composition,
Cultural-Anthropological Composition, and Biological Composition. Socio-Economic Composition is linked to Occupation, Activity, Profession, and Education. CulturalAnthropological Composition consists of variables Race, Nationality, Language, and Religion. Finally, Biological Composition contains variables Sex and Age. In accordance with the instructions on devising causal loop diagrams, a causal loop diagram must be made in the simplest way possible, which is why Age was taken into consideration since the age structure greatly preconditions the fare policy in public passenger transport. Age is comprised of the PreEmployment Contingent which represents the part of the population aged 0-14 in a given area. The Employment Contingent includes residents aged 15-64, while the PostEmployment Contingent refers to residents 65 and above. There is a loop between the variables in that the variables are generally descriptively linked, but a causal loop between them cannot be established in order to quantify the causaleffect reaction. Therefore, we cannot determine which causal-effect loops in the third diagram are positive and which are negative.

A region's economic development indirectly shows the purchasing power of its residents. It is shown by using three sets of indicators related to the income of the population, the budget of the units of local or regional self-government, and 
population employability. Having this in mind, the ultimate model of system dynamics of economic development criteria must be devised in stages by using three smaller causal loop diagrams. The income indicator of development is the first CLD (Figure 2.a), which makes the Income per capita variable directly linked to the region's economic development. The said variable communicates with variables Income and Number of Residents and causal loops can be established towards the variable Income per Capita. Income and Income per Capita are positively linked since an increase in the former means an increase in the latter. However, Population Number and Income are negatively linked because increasing the first causes a decrease of the second variable. Income is positively communicated through variables Capital Income, Income from Employment, Income from Independent Activity, and Income from Property and Property Rights.

The second CLD (Figure 2.b) refers to the indicator of budget income of the unit of local or regional self-government. Budget Income per Capita directly impacts the region's economic development which is in a causal loop with Budget Income and Number of Residents. Budget Income and Budget Income per Capita are positively linked because an increase in the first variable increases the second variable. On the other hand, Number of Residents and Budget Income per Capita are negatively linked because the rise in the first variable causes a drop in the second.

Budget Income is positively impacted by Capital Income, Business Income, and Donation Income. Also, the positive loops between variables Tax Income, Tax-exempt Income communicate with Business Income. Tax Income communicates, with positive loops directed towards it, to Income Tax, Income Surtax, Property Tax, and Goods and Services Tax. The population employability indicator is represented by the third causal loop diagram (Figure 2.c). Its main part is Unemployment Rate which directly impacts economic development. It represents the share of unemployed people in a given area. In other words, the Unemployment Rate communicates with variables Number of Unemployed and Workforce. Causal loops can be established among said variables with direction change towards Unemployment Rate. Numbers of Unemployed and Unemployment Rate are positively linked as the increase in the former leads to an increase in the latter. On the other hand, Workforce and Unemployment Rate are negatively linked because an increase in one leads to a decrease in the other. Workforce is positively affected by Number of Residents, Number of Employed, and Number of Unemployed since the workforce indicator includes all recorded employed and unemployed residents. There is a positive loop ( $\mathrm{R}$ loop) between Number of Employed and Number of Unemployed due to the even number of negative causal-effect loops. A partial occurrence of the same variables is seen in the first, second, and third causal loop diagram, which will ultimately contribute to the merging of the same three diagrams by causal loops in the final model.

The structure of feedback loops in the system of development criteria of public transport can be efficiently outlined by using a system dynamics model, building it through give stages which can then at the final stage be merged into a single ultimate model. The first CLD (Figure 3.a) is related to the density of public passenger transport network. The Public Transport Network Density variable directly impacts the development of public transport in a given area. It represents the relationship between the length of the public transport network and the surface area. Public Transport Network Length and Surface Area communicate with Density. Said variables can be linked using causal loops with a change of direction towards Public Transport Network Density. A positive loop exists between Public Transport Network Length and Public Transport Network Density because an increase in the first variable causes an increase in the second. Surface Area and Public Transport Network Density are negatively linked since an increase in the former causes a decrease in the latter.

Surface Area and PT Network are negatively linked because an increase in the first causes a reduction in the second. Public Transport Network Length communicates with Transport Route Length and Transport Route Number. Said variables are causally linked with directional change towards the PT Network Length. In the communication between Transport Route Length and PT Network Length and Transport Route Number and PT Network Length, positive loops are established since the increase in the first variable also increases the second.

The development of a public transport network is represented by the second causal loop diagram (Figure 3.b). The development is impacted directly by PT Network Development. It is determined based on the length and number of transport routes in a given area. Therefore, Transport Route Length and Transport Route Number communicate with the said variable. Positive loops appear in the communication with direction change towards PT Network Development since the increase in the first variable leads to an increase in the second. The partial occurrence of the same variables in the first and second causal loop diagram will at the last stage, that is, in the final model, lead to a merge of two CLDs.

The third CLD (Figure 3.c) refers to the departure frequency in public transport. The variable that directly affects the PT network is Departure Frequency. It is impacted by Journey Time, Commercial Speed, PT Vehicle Capacity, and Number of Residents. Positive and negative causal loops appear among the said variables with direction change towards Departure Frequency. Positive causal loops appear in the communication between Commercial Speed, PT Vehicle Capacity, and Number of Residents, and Departure Frequency because the increase in the former leads to an increase in the latter. However, the communication between Journey Time and Departure Frequency is marked by a negative loop because an increase in the first variable causes a decrease in the second. Commercial Speed is affected by a positive loop by Infrastructure Quality and PT Vehicle Quality, whereas Commercial Speed is negatively linked to Journey Time, since a higher PT speed leads to lower journey time.

PT Demographic Density (Figure 3.d) is examined in the fourth CLD. PT Demographic Density directly affects the development of PT in a given area. It is obtained from the 


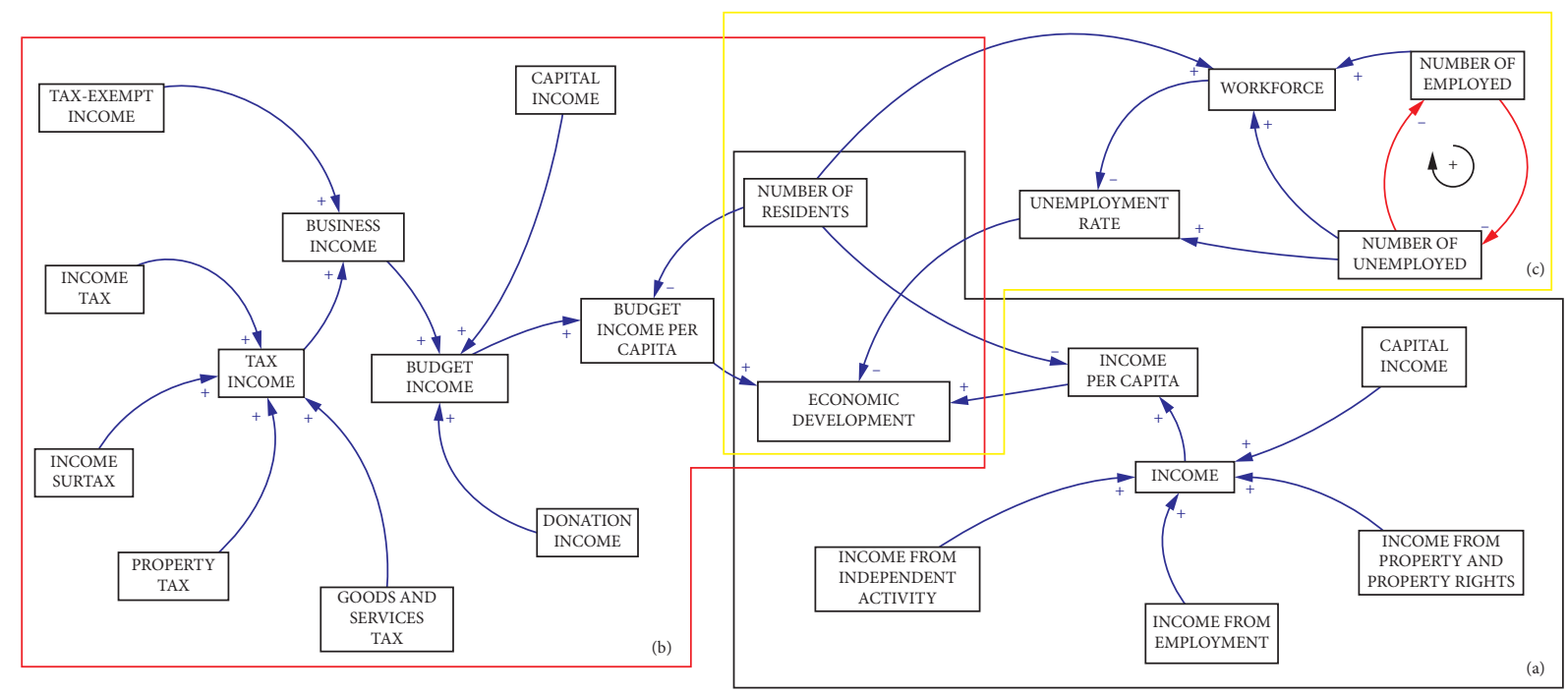

Figure 2: Structure of feedback loops (causal loop diagram) in the system of economic development criteria.

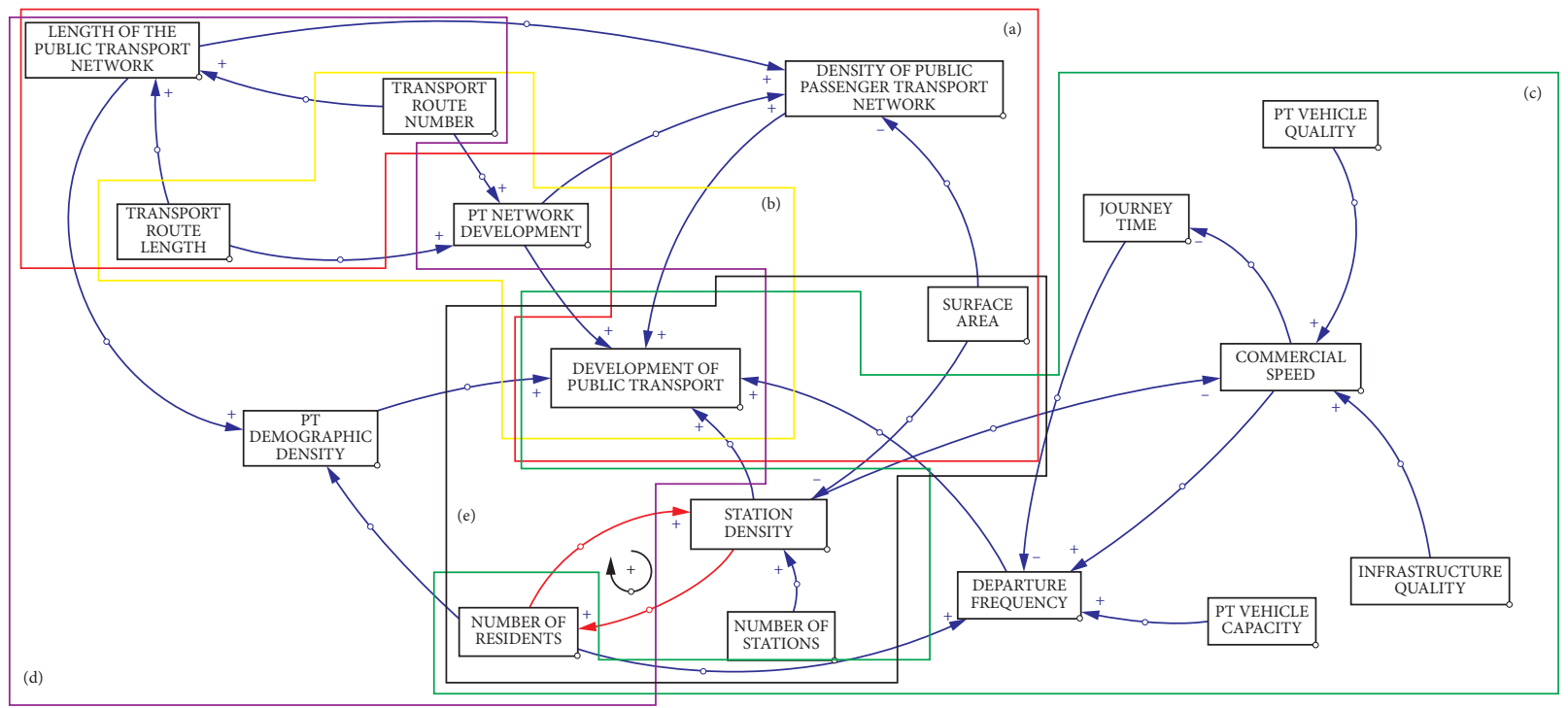

Figure 3: Structure of feedback loops (causal loop diagram) in the system of development criteria of public transport.

relationship between the transport network length and number of residents residing in a given area, meaning that variables PT Network Length and Number of Residents communicate with it, with change of direction towards PT Demographic Density.

A positive loop exists between PT Network Length and PT Demographic Density because an increase in the first variable causes an increase in the second. Number of Residents and PT Demographic Density are negatively linked as an increase in one leads to a reduction in the other. PT Network Length communicates, with positive loops directed towards it, with Transport Route Length and Transport Route Number, both of which appear in the first CLD, which will in the ultimate model lead to a diagram merge.

The fifth CLD describes the impact of station density in $\mathrm{PT}$ on the development of PT in a given area (Figure 3.e). The impact of PT Station Density on the development of PT in an area is direct. PT Station Density communicates with Surface Area, Stations Number, and Number of Residents. Said variables can be linked causally with change direction towards PT Station Density. The latter is positively impacted by Number of Stations because an increase in the number of stations also increases the density of stations. A negative loop occurs between Surface Area and PT Station Density due to a relation in which an increase in the first variable decreases the second. Number of Residents and PT Station Density are positively linked-there is a positive loop $(R)$ because of the even number of negative causaleffect relations. In other words, it is possible to continuously increase the loop in which the increase in the number of people will increase the station density, demand will impact supply. Also, the increase in station density in PT will increase supply which can potentially increase the number of residents in the given area. 
The final model of system dynamics of the transport development criteria achieves a modeling of system dynamics of the criteria that are part of the development system. It makes it possible to initiate the decision-making process on the relevance of some criteria and their inclusion in the equitable fare system model.

\section{Results and Discussion}

System dynamics modeling enables a better understanding of how a complex system works. Using causal loop diagrams achieves the possibility of making decisions on determining equity criteria when determining fare zones in integrated passenger transport.

The structure of feedback loops in the system of demographic development criteria has been shown by modeling system dynamics in stages/parts of a model, as well as the final model of demographic development criteria (Figure 1). A total of 28 variables are outlined, all of which mutually communicate by causal-feedback loops which comprise the model structure. The visualization of the system's central structure enabled us to find the underlying causal loops in the system structure, that is, the selection of equity criteria from the demographic development standpoint. The first variables that directly enter the central variable-Demographic Development-are Population Dispersion, Population Mobility, and Population Composition. Interestingly, said variables are directed towards the central variable, but the causal impact between variables marked by polarity "+" or "”, which denotes the change of dependent variable when the independent variable changes, is not. The reason behind this lies in the fact that the said three variables and structural descriptive variables can be quantified by using sub-variables within the system.

For instance, Population Dispersion communicates with Population Density, which can be quantified, and which is causally impacted by the polarity of Population Number and Surface Area. Thus, we have obtained the first equity criterion from the category of demographic criteria of development-Population Density. The following variable that cannot be quantified but which directly communicates with the central variable is Population Mobility. The said variable communicates with General Population Mobility, which is in turn causally impacted by Birth Rate, Death Rate, Emigration, and Immigration. General Population Mobility can be quantified and thus classified into the second equity criteria. Population Composition and all its branches do not have a causal loop because causal-effect loops cannot be establishing between variables, only communication direction can. Bearing this in mind and taking into consideration the principles of successful system dynamics modeling, we need to consider the specifics of the systems being modeled. Furthermore, we must carry out the analysis of variables to determine the potential benefit of some variables for a specific purpose, in this case, the model of equitable fare system in integrated passenger transport. Population Composition communicates with Socio-Economic Composition, Cultural-Anthropological Composition, and Biological Composition. Socio-Economic Composition and its variables is linked to the economic criteria of development, which are further analyzed for research purposes. Therefore, a consideration of the selection of said criteria within the demographic criteria of development is unnecessary. Cultural-Anthropological Composition considers the demographic development from the standpoint of nationality, language, religion, and race. Considering the specific purpose of the research, it can be concluded that neither of said variables requires their inclusion into the equity criteria. The final variable that communicates with Population Composition is Biological Composition. It considers development based on sex and age.

Dividing population based on sex is inadequate and cannot be seen as an equity criterion of demographic development. The population division based on age includes variables Pre-employment Contingent, Employment Contingent, Post-employment Contingent. For supply and demand in public passenger transport to be functional, the most significant participant of the system is the population that belongs to the working contingent. The pre-employment and post-employment contingent in PT system is usually subsidized and represents groups that have special fares. In the working contingent, however, this is not the case, and this should be taken into consideration when selecting equity criteria of demographic development. The third equity criterion for determining fare zones in integrated passenger transport and the last of the demographic criteria of development is Employment Contingent, which indicates the development of an area from the standpoint of the population aged 15-64. In demographic statistics, the term Employment Contingent is common. Employment Contingent refers to the number of inhabitants of a certain age, i.e., the population aged 15 to 64 inclusive, which is considered the working-age population [29] concerning theoretical physiological ability. Therefore, in our criteria definition, we have considered the employment contingent as a necessary criterion from the demographic group of criteria. Concerning the Pre-Employment and Post-Employment contingent (children, schoolchildren, and pensioners), this group is dominant in daily migrations, which significantly affects the transport demand and thus the determination of the price of transport.

The economic criteria of development were shown by modeling system dynamics in three stages and as a final model of economic criteria of development (Figure 2). A total of 23 variables were shown that mutually communicate with causal-feedback loops and thus comprise the model structure. The visualization of the system's central structure has ensured a way to find the underlying causal loops in the system structure and a way to choose equity criteria from the standpoint of economic development. The first variables that directly enter the central variable Economic Development are Unemployment Rate, Income per Capita, and Budget Income per Capita. All three variables have a direction towards and causal impact on the central variable. They also indicate the change in the dependent variable once the independent variable changes. This obtains all three equity criteria from the economic development criteria category, that is, Unemployment Rate, Budget Income per Capita, and 
Budget Income per Capita. Other variables included in the structure of feedback loops of the system dynamics of economic development criteria directly communicate with and impact on the outcome of said three equity criteria. As such, they cannot be classified as relevant criteria because some results in the model might appear several times, which would affect model accuracy. Income per Capita and Budget Income per Capita communicate with the central variable by positive causal loops because an increase in one variable leads to an increase in the other. Therefore, a greater income per capita and budget income per capita will generate greater development of the observed area and in an equitable model, lead to a greater charge in more developed areas. The third variable-Unemployment Rate-communicates with the central variable by a negative causal loop, because an increase in the first variable leads to a decrease in the second. In other words, the greater the unemployment rate, the lower the development of the observed area.

The structure of feedback loops in the system of transport development criteria was shown by modeling system dynamics in five stages-parts of the model-and in the final model of transport criteria of development (Figure 3). A total of 17 variables were shown that communicate by causal-feedback loops and comprise the structure of the model. The visualization of the system's central structure has ensured a way to find the underlying causal loops in the system structure, that is, the selection of equity criteria from the standpoint of transport development. The first variables that directly enter the central variable-PT Development-are Network Density, PT Network Development, PT Demographic Density, Departure Frequency, and PT Stations Density. All five said variables are directed towards the central variable, and the causal impact between all variables is indicated by polarity "+", which indicates the positive change in the dependent variable once the independent variable changes. The remaining variables that are part of the feedback loop structure of the system dynamics of economic development criteria directly communicate with and impact on the outcome of said five equity criteria. They cannot be classified as relevant criteria because some results might reoccur, rending the model inaccurate. The specificity of the feedback loop structure at transport development criteria is the occurrence of direct communication between variables that directly affect the central variable. This refers to the communication between PT Network Development and PT Network Density in the direction of PT Network Density. Furthermore, it is evident that the improvement of PT network development leads to an increase in PT network density. Similarly, the structure within the said variables reveals that PT network length also impacts the PT network density. The network length depends on the length and number of transport routes that are an integral part of the PT network development. Therefore, the PT Network Development is not included in the equity criteria category, because its features make it a part of that system since it directly impacts on and communicates with PT Network Density. We have thus obtained four equity criteria from the transport development criteria-PT Network Density, PT Demographic Density, Departure Frequency, and PT Station
Density. All four variables communicate with the central variable by positive causal loops because an increase in one variable causes an increase in another. Bearing this in mind, it can be stated that a greater network density, demographic density, departure frequency, and station density can generate higher development of a given area and in an equitable model have a greater charge in the more developed areas.

\section{Conclusion}

The issue of equal access for all public transport users and balanced development of areas included in the public transport network leads to a need for changing the current fare systems into a system based on equity. The first step in developing an equitable fare model is to define equity criteria for determining fare zones in integrated passenger transport which would enable an overview of development of certain areas-zones-and outline the differences and equality in the transport, economic, and demographic sense. This research has defined such equity criteria as a requirement for devising an equitable fare model that would ensure an equitable change of transport fares within zones. Future research should focus on evaluating the defined equity criteria and developing the model of equitable fare systems whilst using the said criteria. The application of an equitable fare model in practice ensures the equitable charge of public transport services by working in favor of participants that are in a more unfavorable position, all with the aim to ensure equality. A review of the literature and analysis of existing fare systems concludes that the distance-based fare and zonal fare models do not provide equal accessibility of transport services to all stakeholders. Accessibility refers to a situation in which the financial cost of travel does not represent an obstacle and inability to access an individual or group of people. Given the above, we can say that distance-based and zonal fare systems (affected by travel kilometers and zone size) are not fully accessible to all. An individual or a group of people living in an area with inadequate public transport services or who have low incomes cannot obtain public transport services. Then public transport stops being public, and transport becomes inaccessible, and the individual or society becomes marginalized. After defining equity criteria and developing an equity fare model, the precondition will be met to apply it in practice. If this happens, it would mean that a change from equality to fairness and price regulation has been achieved from the point of view of equal traffic economic and demographic development of each fare zone in integrated passenger transport. The introduction of an equity fare system largely depends on the political stakeholder who understands and wants to apply the principles of equity in public passenger transport organizations. Such a system reduces transport disadvantages and the exclusion of individuals and groups from the standpoint of public transport. It increases transport demand in rural and less developed areas because fares are adjusted to the region's developmental features. The mission and vision of public passenger transport is thus achieved because it becomes equally available to everyone, under equitable, but not equal, conditions that had thus far been observed by equal price per 
kilometer of travel, and not according to the equal quality of the transport service or an equal economic or demographic development.

\section{Data Availability}

The data used to support the findings of this study are included within the article.

\section{Conflicts of Interest}

The authors declare that they have no conflicts of interest.

\section{References}

[1] H. W. Hamacher and A. Schöbel, "Design of zone tariff systems in public transportation," Berichte des Fraunhofer ITWM, vol. 21, 2001.

[2] M. Koháni, "Tariff zones design in integrated transport systems: A case study for the žilina municipality," Mechanical Engineering Energy, vol. 1, pp. 91-97, 2015.

[3] M. Koháni, "Exact approach to the tariff zones design problem in public transport," in Proceeding of the 30th International Conference Mathematical Methods in Economics Exact, pp. 426-431, September 2012, https://doi.org/90C08.

[4] D. Huang, Z. Liu, P. Liu, and J. Chen, "Optimal transit fare and service frequency of a nonlinear origin-destination based fare structure," Transportation Research Part E: Logistics and Transportation Review, vol. 96, pp. 1-19, 2016.

[5] P. Kopecká and J. Švetak, "The integrated public transport system," Science Journal of Merit Research.vol. 1, pp. 149-156, 2013.

[6] D. Šipuš, B. Abramović, and S. Gašparović, "Equity fare system: factors affecting fare structure in integrated passenger transport," Transportation Research Procedia, vol. 40, pp. 1192-1198, 2019.

[7] V. Čavrak, Transport Economics, Škola za cestovni promet, Zagreb, Croatia, 2002.

[8] D. Šipuš and B. Abramović, "Tariffing in integrated passenger transport systems: A literature review," Promet-Traffic \& Transportation, vol. 30, pp. 745-751, 2018.

[9] K. Jansson, "Optimal public transport price and servise frequency," Journal of transport, Economics and Policy, vol. 27, 1993.

[10] D. Šipuš, Modeling of Equity Fare Systems in Integrated Passenger Transport, Doctoral Dissertation, University of Zagreb, Faculty of Transport and Traffic Sciences, Zagreb, Croatia, 2020.

[11] X. Chen, M. Yin, M. Song, L. Zhang, and M. Li, "Social welfare maximization of multimodal transportation," Transportation Research Record: Journal of the Transportation Research Board, vol. 2451, no. 1, pp. 36-49, 2014.

[12] Š. Čarný, V. Zitrický, and D. Šipuš, "Harmonization of transport charging in Slovak republic," LOGI - Scientific Journal on Transport and Logistics, vol. 11, p. 12, 2020.

[13] L. A. Guzman, D. De, and G. Circella, "Case Studies on Transport Policy Evaluation of synergies from transportation policy packages using a social welfare maximization approach: A case study for Madrid, Spain," Case Study Transport of Policy, vol. 3, no. 1, 2014.

[14] J. Holmgren, "A strategy for increased public transport usagethe effects of implementing a welfare maximizing policy," Research in Transportation Economics, vol. 48, pp. 221-226, 2014.
[15] D. Houston and S. Tilley, "Fare's fair? Concessionary travel policy and social justice," Journal of Poverty and Social Justice, vol. 24, pp. 187-207, 2015.

[16] S. Gašparović, "Theoretical postulates of transport disadvantage," Hrvatski Geografski Glasnik, vol. 78, pp. 73-95, 2016.

[17] K. Martens, Transport Justice: Designing Fair Transportation Systems, Routledge, New York, NY, USA, 2017.

[18] L. Babel and H. Kellerer, "Design of tariff zones in public transportation networks: theoretical results and heuristics," Mathematical Methods of Operations Research, vol. 58, no. 3, pp. 359-374, 2003.

[19] R. Borndörfer, M. Karbstein, and M. E. Pfetsch, "Models for fare planning in public transport," Discrete Applied Mathematics, vol. 160, pp. 2591-2605, 2012.

[20] H. W. Hamacher and A. Schöbel, On Fair Zone Designs in Public Transportation, vol. 430, pp. 9-11, 1995.

[21] A. Schöbel, Optimization in Public Transportation, Springer, Boston, MA, USA, 2006.

[22] A. Schöbel, "Fair zone design in public transportation networks," in Proceedings of the International Conference on Operations Research, pp. 191-196, Berlin, Germany, August 1995.

[23] B. Barabino, C. Lai, and A. Olivo, Fare Evasion in Public Transport Systems: A review of the literature, Public Transport, Springer, Berlin, Germany, 2020.

[24] M. Štastná and A. Vaishar, "The relationship between public transport and the progressive development of rural areas," Land Use Policy, vol. 67, pp. 107-114, 2017.

[25] D. Šipuš, B. Abramović, L. Černá, and E. Nedeliakova, "Transport demand analysis in the rural area: the case study of sisak - moslavina county," in Proceedings of the Fourth International Conference on Traffic and Transport Engineering, O. Čokorilo, Ed., p. 9, Beograd, Serbia, August 2018.

[26] L. V. Bertalanffy, General System Theory: Foundations, Development, Applications, George Braziller, New York, NY, USA, 1968.

[27] J. Sterman, Business Dynamics: Systems Thinking and Modeling for a Complex World, McGraw-Hill, New York, NY, USA, 2000.

[28] A. Turina, "Primjena metodologije sistemske dinamike u analizi stanovništva," Migracijske i Etničke Teme, vol. 25, pp. 189-211, 2009.

[29] Državni zavod za statistiku, 2018, https://www.dzs.hr. 